\title{
Family structure, time constraints, and sport participation
}

\author{
Jane E. Ruseski • Brad R. Humphreys • \\ Kirstin Hallmann • Christoph Breuer
}

Received: 7 January 2011 / Accepted: 28 June 2011 /Published online: 15 July 2011

(C) European Group for Research into Elderly and Physical Activity (EGREPA) 2011

\begin{abstract}
Recent research emphasizes the importance of economic factors on sport participation. We extend this by examining the role played by time constraints and family structure in survey data from Rheinberg, Germany. Based on empirical models that account for the two-part decision - the decision to participate and the decision about how long to participate-involved, we find that time constraints in the form of time spent caring for children and relatives and family structure in the form of the presence of children reduce both the likelihood that individuals participate and the time spent taking part in sports.
\end{abstract}

Keywords Physical activity. Time allocation.

Family structure

\section{Introduction}

The health benefits of regular physical activity are well documented in the clinical and public health literature; yet,

J. E. Ruseski $(\bowtie) \cdot$ B. R. Humphreys

Department of Economics, University of Alberta,

HM Tory 8-14,

Edmonton, AB T6G 0T3, Canada

e-mail: ruseski@ualberta.ca

B. R. Humphreys

e-mail: brad.humphreys@ualberta.ca

K. Hallmann $\cdot$ C. Breuer

Institute of Sport Economics and Sport Management,

German Sport University,

Cologne, Germany

K. Hallmann

e-mail: k.hallman@dshs-koeln.de

C. Breuer

e-mail: Breuer@dshs-koeln.de the World Health Organization (WHO) estimates that up to $60 \%$ of the world's population is not sufficiently active to obtain health benefits [1]. Many developed nations have sport policies that call for a higher proportion of its citizens to be involved in sports activities. A critical component to achieving these goals is to understand the differential causal effects of economic, social, and ecological factors on individuals' decisions to participate in sport. Therefore, it is important to understand why some people regularly participate in sport while others do not or why people start and stop exercising regularly. A better understanding of how people combine time and purchased inputs to engage in competing activities and the impact of family structure and time allocation is needed. Indeed, time constraints are frequently reported barriers to exercise. Time constraints can take the form of care for children and relatives. Child care represents an important time constraint for relatively young adults, while caring for relatives represents an important time constraint for older adults, and the importance of this constraint will grow as the populations of developed and developing countries age. It was shown for example that time for care of children and relatives impacts regular sport activity negatively. In contrast, working time (respectively school time) has a positive effect on sport participation [2]. Having infants or school-aged children in the household and caring for them reduces the sport participation of the parents [3-5]. This indicates interdependencies between family structures, time and sport participation. Yet, so far, not recognized in this context is the children's sport participation, which is also part of family structure. The purpose of this paper is to analyze the impact of family structure, including children's sport participation and time constraints on sport participation.

This contribution is structured as follows: first, an overview of the relevant literature examining the impact 
of family structure and time constraints on sport participation is presented; second, the theoretical model motivating the empirical analysis and the empirical approach taken in this paper is presented. The data used in the analysis are described thereafter. The results are given next, followed by the discussion and a conclusion.

\section{Literature review}

First, a definition of sport participation is offered, as there is no common agreement on a definition in the existing literature. Researchers generally take either a broad or narrow view of sport participation. A broad view of sport includes activities like gardening, walking, and occasionally riding a bike. This perspective is often taken when the interest is on examining sport participation in general $[5,6]$ while others explicitly focus on sports in a narrow sense [7] which excludes activities that are not clearly sport. Moreover, some definitions add the dimensions of frequency and duration to sport participation. On the one hand, sport participation is defined as having been physically active during the last 4 weeks [6], while on the other hand, sport participation is described as having practiced sports within the last fortnight [7]. While the dimension of frequency is included in those definitions, the duration is not included. Both dimensions are included in a definition provided by Sport England [8], "Participation in each sport is defined as the percentage of the adult population (age 16 plus) who have taken part in the sport at moderate intensity for $30 \mathrm{~min}$ or more at least once in the last week (at least 4 days out of the previous 28 days)." In this paper, sport participation is defined broadly to include sport activities like playing football and swimming as well as "leisure" activities such as going for a walk or riding the bike, which are undertaken at least once per week for at least $30 \mathrm{~min}$. However, activities such as gardening or walking the dog are excluded.

There are several studies on sport participation, on the one hand emphasizing insights from a sociological perspective [7,9], and on the other hand from an economic perspective $[5,6,10,11]$. The determinants of sport participation in general have been investigated $[4,5,12-$ 19]. Measures of family structure such as household size and marital status are routinely included in studies of sport participation, but these variables are less likely to be the primary focus of the analysis. In this sense, less attention has been given to the interplay of family structure, time allocation, and sport participation. Nonetheless, children's sport participation has not been widely studied. This paper begins to address that gap by analyzing the effect of family structure and time constraints on decisions about sport participation.
Family structure

The structure of a family influences sport participation. Especially, the existence of children and the marital status have an impact on the sport activity of single family members. It is shown that having infants or school-aged children in the household and caring for them reduces the sport participation of the parents $[2-5,20]$. Consequently, being childless has a positive relationship with sport [21]. The time required for child care increases as the number of children living in the household increases. Each additional child in the household reduces the probability that an individual participates in some kind of physical activity [6]. This reflects a greater responsibility for women in childcare and home production activities than for men [6]. In contrast, it is indicated that the number of children has a positive effect on the sport participation for men but no effect on the activity of women [22]. Therefore, contradicting findings can be reported regarding the influence of having children and caring for them on sport participation.

Additionally to the time spent for caring of children, the time devoted to caring for relatives has a negative impact on sport participation [2]. An increase in the number of adults in the household reduces the probability of sport participating as well [20]. The findings concerning the impact of the marital status on sport participation are mixed. On the one hand, married people are less likely to participate in sport because household commitments reduce the amount of time available for sport participation [6, 22]. Especially in commercial sport clubs, the percentage of singles is higher, because the motives for doing sport are often connected with the issue of looking for more social contacts [23]. On the other hand, it is suggested that married people participate more in sport activities than unmarried people $[20,24]$. Moreover, there are results that there is no correlation between marital status and sport participation [25]. Singles spend more time on leisure activities such as playing musical instruments, singing, acting, and dancing than married people, but married people are more engaged in active sport participation [24].

Besides the presence of children and marital status, the participation in sport of other family members has a positive influence on sport participation of children and adolescents. They participate more in sports when their parents and siblings also participate [26, 27], whereupon the influence of a mother's sport activity is higher than the activity of the father on boys and girls. Family member's sport activity is similar to one another's in terms of health status and health behaviors [28]. For older people, the support of the family for being active is important as they are more likely to participate in sport when they receive support from their family and friends [29]. Family structure plays an important role in women's sport participation 
decisions. Women are more likely to participate in sport when they are younger, white, college-educated, and without young children at home. In contrast, women with a higher involvement in household/caring activities and a lower sport participation level are older, married with young children at home, and not employed [21].

\section{Time constraints}

There is an association between family structure and time constraints. Shortage of time often results from commitments to the family, and it is also dependent on employment status. As stated above in the section about family structure, the time for raising children and caring for relatives has a negative effect on sport participation [2]. The presence of children younger than 18 in the household has a negative effect on time spent for leisure activities in general. Households with children younger than 18 have more time constraints; therefore, the time available to spend on leisure activities is reduced [24]. Labor force participation also has a negative effect on leisure time as full-time employed individuals spend less time per day on leisure activities than the nonworking individuals [24]. Studies examining employment status and sport participation produced mixed findings. Some studies report that working time (respectively school time) has a positive effect on sport participation [2]. An explanation for that can be that people with a high workload take part in sports to compensate for the work life [30]. Other research indicates that working time has a small but significant negative effect on sport participation $[20,31]$. The frequency of participation in a specific sport activity is likely to decrease as a result of the involvement in paid, unpaid, and voluntary work [5]. Barriers for taking part in exercise could be the lack of time due to long working hours and exhaustion after work [32]. Hence, unemployed people do more sport than employed as employed people have less free time for participating in sport $[6,22,23]$. With regard to marital status, the overall time spent on leisure decreases among married individuals as household income level increases, perhaps indicating that more time must be spent in acquiring the additional income, leaving less time for leisure [24]. Pertaining to sport participation of adolescents, their involvement in sport decreases by moving from college to fulltime employment, because less free time is available [27]. Moreover, the time needed to reach the facility where the sport is performed needs to be taken into consideration as well [33]. Instead of using travel time, travel distance was used in studies highlighting its importance for the use for sporting activities. The number of nearby facilities correlates positively with physical activity [34-36]. Consequently, facilities located near home (e.g. within suburbs) are used more often and by more people than facilities located elsewhere.

\section{Empirical analysis of sport participation}

Theoretical model

The theoretical model motivating the empirical analysis in this paper is an economic model of participation and time spent in physical activity developed by Humphreys and Ruseski [6] that is grounded in Becker's [37] model of time allocation. The key behavioral decisions in the model are the separate but related decisions to participate in sport and how long to participate per episode of exercise. The objective function highlights the two-part decision underlying sport participation. Individuals maximize utility by allocating time to participation in sport and all other activities (such as sleeping, sedentary leisure, working for pay and working at home, including childcare) and purchasing a bundle of goods and services subject to time and budget constraints. The utility function is $U(a, t, z)$ where $a$ represents the individual's decision to participate in sport; $t$ is the amount of time spent per episode of activity; and $z$ represents the individual's decision to engage in the other activities.

Individuals' time allocation choices are constrained by budget and time constraints. The budget constraint is $Y=$ $F_{a}+c_{a} a t+c_{z} z$ where $Y$ is money income; $F_{a}$ is the fixed cost of engaging in physical activity; $c_{a}$ is the variable cost associated with engaging in sports; and $c_{z}$ is the cost all other goods and services. The time constraint is $T^{*}=$ $a t+\theta z$ where $T^{*}$ is the time available for consumption activities such as sports and $\theta$ is time spent consuming $z$. Assume that $T^{*}, t$, and $\theta$ are measured in the same units such as hours. Let $T$ be the total time available for work and all other activities. Hence, $T^{*}=T-h$ where $h$ is time spent working. If individuals can choose the amount of hours they work, then $h$ is endogenous and wage earnings $w$ can be expressed in terms of total time available and time spent not working: $w h=w(T-a t-\theta z)$. This equation captures the notion that any time spent in sports activity and other activities is time not available for work and reduces earnings. Thus, the wage is the opportunity cost of engaging in activities other than work. The full budget (or income) constraint includes the opportunity cost of time $y_{0}+w T=$ $F_{a}+p_{a} a t+p_{z} z$ where $y_{0}$ is exogenous income; $w T$ is potential income if individuals spend all of their time working; $p_{a}=c_{a}+w$ is the full cost of participating in sports activities; and $p_{z}=c_{z}+\theta w$ is the full cost of participating in other activities. Consumers choose $a, t$, and $z$ to maximize utility subject to the full budget constraint.

The full budget constraint shows that individuals have a fixed amount of time to devote to all activities, including 
work, commuting, leisure, household production, child rearing, and other activities. The full budget constraint links income to both spending on activities and the opportunity cost of time through work. The solution to this constrained utility maximization problem gives rise to expressions that describe the separate but related decisions of participation in sport (the extensive margin) and time spent (the intensive margin). Details on the solution of this model can be found in [6]. First, consider decisions on the extensive margin. Decisions about participation are described as being made on the extensive margin because it is a discrete decision that must be made first but does not describe the intensity of participation. Individuals must first decide whether or not to engage in physical activity. This decision can be described by the following equation:

$a_{i}^{*}=\alpha^{\prime} X_{i}+\varepsilon_{i}$

where $a_{i}^{*}$ is an unobservable indicator variable that determines whether or not individual $i$ participates in physical activity, $X_{i}$ is a vector of economic, demographic, family structure, and time allocation factors that affect individual decisions to be physically active, and $\varepsilon_{i}$ is an unobservable random variable capturing all other factors affecting individual decisions to participate in physical activity. This decision is characterized as a "hurdle" in the literature since it captures the idea that the overall economic benefit generated by participation in physical activity must exceed some level before a person is observed participating in physical activity.

Next, consider decisions made on the intensive margin. Decisions about how much time to spend taking part in physical activity are described as being made on the intensive margin because they are made after the decision to participate is made and describe the intensity of participation. Time spent participating in physical activity can be described by the following equation:

$t_{i}^{*}=\beta^{\prime} Z_{i}+v_{i}$

where $t_{i}^{*}$ is a latent variable that captures the utility that individual $i$ gets from devoting time to physical activity, $Z_{i}$ is a vector of variables measuring economic, demographic and family structure characteristics of individual $i$ that affect the amount of time spent. Note that the variables included in $X_{i}$ and $Z_{i}$ need not be the same. $\nu_{i}$ is an unobservable random variable that captures all other factors that affect individual $i$ decision about the amount of time spent being physically active. $\alpha$ and $\beta$ are vectors of unobservable parameters to be estimated. This decision is also characterized as a "hurdle" in the literature since, conditional on deciding to participate, individuals still must decide to devote time to physical activity. These two latent variable representations of the theoretical model motivate the empirical models.
Empirical models

The primary focus of the empirical analysis in this paper is the effect of family structure and time constraints embodied in the household budget constraint on individual decisions about sport participation and time spent practicing sport. The empirical analysis proceeds in two steps. First, single equation probit models of the participation decision are estimated in which $X_{i}$ is expanded to include variables measuring time spent in activities like work, childcare, and caring for relatives. This probit model can be motivated by Eq. 1, which describes the decision to participate in sport. This step allows for a detailed exploration of the effect of time constraints and family structure variables on decisions about sport participation. Second, empirical models based on the two-part decision process described by Eqs. 1 and 2 are estimated in which $X_{i}$ and $\mathrm{Z}_{i}$ contain variables measuring demographic characteristics, employment status, and family structure. In this case, we assume that $X_{i}$ and $Z_{i}$ and the vectors of parameters $\alpha$ and $\beta$ are identical. Under these assumptions, the two-part model decision process described by Eqs. 1 and 2 can be estimated using the familiar Tobit maximum likelihood estimator, often called the Tobit Type I model.

The Tobit approach accounts for the possibility that some people are not physically active and are assigned a zero for the variables describing both sport participation and time spent practicing sport. It assumes that these zeros represent "genuine zeros" as described by Jones [38], meaning that the observed non-participation in sport is the result of the utility maximizing choices, as described in the theoretical model, of sampled individuals. In the context of Eq. 1, the value of the latent variable $a^{*}{ }_{i}$ is relatively small for nonparticipants. Jones [38] discusses the appropriate econometric techniques for dealing with zeros that are the result of utility maximizing decisions in survey data and identifies the Tobit model as one appropriate approach to dealing with these "genuine" zeros in survey data.

Other approaches for dealing with the presence of zeros in survey data exist. Jones [38] discusses these alternatives, which include two-part models and double-hurdle models. The double-hurdle model is the most commonly used alternative to the Tobit Type I model in the physical activity and sport participation literature. The Tobit model is a special case of the double-hurdle model in which the factors that affect the participation decision and the time spent decision are assumed to have the same sign; in the doublehurdle model, these factors can have different signs, as separate parameters are estimated on each explanatory variable in the participation and time spent equations. The double-hurdle model is also difficult to estimate in smaller samples, as the shape of the joint likelihood function often contains non-convex regions, and evaluating the likelihood 
function can be computationally difficult in these samples. It was not possible to estimate a double-hurdle model in this particular sample, due to convergence problems. The Tobit Type I model estimated in this analysis also accounts for the separate but related participation and time spent decisions, although in a somewhat restricted manner when compared to the double-hurdle model.

\section{Data description and summary statistics}

In 2009, the inhabitants of the town of Rheinberg-a small town with a population of 32,556 in the German federal state of North Rhine Westfalia-were surveyed by means of a Computer-Assisted Telephone Interview (CATI). The lastbirthday method was used to identify the interview partner in the household. Every household was called up to ten times to reach an interviewee. A total of 1,526 interviews were conducted. The questionnaire also included questions for children which were answered by their parents. Hence, 408 cases of 3- to 17-year-old children were added so that the overall sample is 1,934 .

Decisions about participation and time spent taking part in sport are analyzed using data from this population survey. The questionnaire was developed to get information about household sport participation, attitudes about sport participation, and parental or peer influence on sport participation. The questionnaire contained questions about sport participation like "Do you practice sport in your freetime?" as starting point for questions about sport participation. Thereafter, questions about the first and second most often practiced sports throughout the last year were posed before the weekly frequency and duration of those sports was interrogated. In addition to detailed questions about sport participation, the respondents were asked for their time spent in many activities like work, childcare, and care of relatives; monetary costs of participation; and nonmonetary costs of time spent getting to sporting facilities. In addition, data to construct factors that have been repeatedly documented as associated with sport participation like age, income, education, gender, and migration background are available in the survey. The descriptive statistics from the sample of adults for variables that are used in the empirical analysis is presented in Table 1.

The sample used in the empirical analysis contains 1,453 adults between the ages of 18 and 70 . Sport participation and time spent practicing sport are the key variables of interest. The sport participation variable is based on responses to the questions: "Do you practice sport in your free time," "Which is the first and second most often practiced sport?," "How often did you practice this sport during the last week," and finally, "How many minutes per week do you spend doing your most frequently practiced
Table 1 Summary statistics

\begin{tabular}{lrr}
\hline Variable & \multicolumn{1}{l}{ Mean } & Std. Dev. \\
\hline Physically active & 0.68 & 0.47 \\
Time spent (h/week) & 1.37 & 1.53 \\
Age & 51.92 & 17.57 \\
Age squared & 3004.57 & 1806.03 \\
Male & 0.48 & 0.50 \\
Employed & 0.56 & 0.50 \\
Education (<10 years) & 0.63 & 0.48 \\
Education (12-13 years) & 0.23 & 0.42 \\
Education (>17 years) & 0.14 & 0.34 \\
Native & 0.94 & 0.24 \\
Single & 0.17 & 0.37 \\
Household size & 2.60 & 1.24 \\
Has kids & 0.26 & 0.44 \\
Has kids $<3$ & 0.01 & 0.10 \\
Kids active (h/week) & 0.40 & 0.98 \\
Travel time to sport facility (min) & 9.73 & 59.36 \\
Hours worked & 22.44 & 22.99 \\
Hours childcare & 7.30 & 20.23 \\
Hours relative care & 1.34 & 12.21 \\
$N$ & 1,453 & \\
\hline & &
\end{tabular}

sport." Individuals who responded yes to the first question and have a positive number of minutes spent per week are treated as participating in sports. Based on this definition, nearly $70 \%$ of the sample participates in sports. This finding is consistent with previous research on sport participation in other communities in Germany [39, 40]. The time-spent variable is constructed as the sum of minutes spent per work practicing the first and second most practiced sports divided by 60 . The average amount of time spent per week is $1.37 \mathrm{~h}$.

The covariates used in the statistical analysis reflect factors commonly used in physical activity/sport participation research. The only economic variables included are employment status and hours worked. Although individuals were asked about their household and personal incomes, nearly half the sample did not respond to this question. Thus, including income and hourly wage would result in losing nearly half the sample due to missing observations. Fifty-six percent of the sample is employed and reported working just over $22 \mathrm{~h} /$ week.

Of particular interest in this analysis are the variables related to family structure (having children, single, and size of household) and time constraints in addition to hours spent working (hours spent caring for children and relatives and time required to get to the facility where the individual practices sport). Looking first at family structure, the majority of the sample is either married or living with someone else as only $17 \%$ of the sample reported being 
single. Twenty-six percent of the sample has children but only $1.0 \%$ of the sample has children under the age of 3 in the household. The average household size is 2.6. The average number of hours spent per week caring for children is 7.30 and $1.34 \mathrm{~h}$ are spent on average for caring for relatives. On average, individuals spend less than $10 \mathrm{~min}$ traveling to their sport facility.

Other socio-demographic variables included in the analysis are age, gender, education, and native German. Again, these covariates are commonly included in studies of sport participation. Age is allowed to enter nonlinearly by including age and age-squared. The average age of the sample is 53 years old. Education is also allowed to enter nonlinearly by including three education levels: less than 10 years; between 12 and 13 years; and 17 years. Twentythree percent of the sample has 12 or 13 years of education and $14 \%$ has 17 years of education. Forty-eight percent of the sample is male. The majority of the sample is native German (94\%).

\section{Results and discussion}

Family structure, time constraints, and participation decision

We first undertake a detailed examination of the effect of time constraints and family structure on the decision to participate in sport. From the full budget constraint, individuals have a fixed amount of time to devote to all activities, including work, commuting, leisure, household production, child rearing, and other activities. The survey used in this study contained questions permitting construction of variables that are not commonly available in other data sources like hourly wage, household size, presence of young children in the household, children's participation and time spent in sport, attitudes about sport participation, and time allocated to work, childcare, sport participation, and relative care. This study extends previous studies of sport participation by including such variables as covariates. The additional explanatory variables in the probit model measuring family structure are: marital status; the presence of children under three in the household; an indicator variable for multi-person households; and the amount of time children spent practicing sport. The time constraint variables are: travel time to the sport facility in minutes; hours worked; hours spent providing childcare; and hours spent providing care to relatives.

Table 2 shows the parameter estimates from three probit models, transformed into probability derivatives, and the $p$ value for two-tailed tests of the null hypothesis that the parameter estimates are equal to zero. Probability derivatives show the effect of one unit change in the explanatory variable on the probability that the dependent variable is equal to one; in this case, the probability that an individual is observed participating in sport.

The approach taken to reporting the results of the probit models is to first estimate and report the result of a

Table 2 Probit results: marginal effects for sport participation

\begin{tabular}{|c|c|c|c|c|c|c|}
\hline & \multicolumn{2}{|l|}{ Baseline model } & \multicolumn{2}{|l|}{ Family structure } & \multicolumn{2}{|l|}{ Time constraints } \\
\hline & Marginal effect & $p$ Value & Marginal effect & $p$ Value & Marginal effect & $p$ Value \\
\hline Age & 0.0065 & 0.094 & 0.0081 & 0.054 & 0.0084 & 0.047 \\
\hline Age squared & -0.0001 & 0.068 & -0.0001 & 0.046 & -0.0001 & 0.039 \\
\hline Male & -0.0540 & 0.032 & -0.0555 & 0.029 & -0.0626 & 0.024 \\
\hline Employed & 0.0209 & 0.533 & 0.0212 & 0.528 & 0.0374 & 0.516 \\
\hline Education (12-13 years) & 0.0841 & 0.007 & 0.0818 & 0.009 & 0.0818 & 0.009 \\
\hline Education (>17 years) & 0.0828 & 0.025 & 0.0857 & 0.021 & 0.0772 & 0.040 \\
\hline Native & 0.1446 & 0.006 & 0.1389 & 0.008 & 0.1448 & 0.006 \\
\hline Single & & & 0.0073 & 0.862 & 0.0012 & 0.977 \\
\hline Has kids & & & -0.1211 & 0.013 & -0.0710 & 0.196 \\
\hline Household size & & & 0.0206 & 0.218 & 0.0222 & 0.182 \\
\hline Kids active (h/week) & & & 0.0457 & 0.027 & 0.0494 & 0.018 \\
\hline Travel time to sport facility (min) & & & & & 0.0014 & 0.000 \\
\hline Hours worked & & & & & -0.0009 & 0.467 \\
\hline Hours childcare & & & & & -0.0021 & 0.010 \\
\hline Hours relative care & & & & & -0.0034 & 0.005 \\
\hline$N$ & 1,453 & & & & & \\
\hline
\end{tabular}

$p$ Values for $z$ statistics 
"baseline" probit model that contains common explanatory variables used in previous empirical research on participation in sport and physical activity. These variables include age and age squared to account for a nonlinear relationship between age and sport participation, an indicator variable for gender, variables capturing education, and an indicator variable for native Germans to capture nationality. This allows an assessment of how the results based on the sample from Rheinberg, Germany compares with the results of previous studies. Variables capturing family structure and time constraints are added to this baseline probit model. The results of these extended models are also reported in Table 2. Comparing the parameter estimates of the commonly included covariates across Models 1, 2, and 3 provides an assessment of the robustness of the commonly included covariates to the addition of new family structure and time constraint variables.

From Table 2, the results for the "baseline" model a weak inverse $U$ relationship between age and sport participation. The probability that an individual participates in sport initially rises with age and then declines after peaking sometime in middle age. This pattern, reported in other studies of participation in physical activity and sport, implies that the young and old are less likely to participate in sport than others. Males in this population are less likely to participate in sport. Sport participation increases with education, and native Germans are more likely to participate than the non-natives. With the exception of the gender effect, these determinants of sport participation are similar to others reported in the literature. A possible explanation for the finding that women are more likely to participate in sport than men may be that walking is included as a sport in the survey. Walking is often the most frequently reported physical activity and women are more likely to walk than men.

The next probit model adds a vector of variables capturing family structure in order to assess the effect of family structure on participation in sport holding the other characteristics constant. Family structure appears to affect the probability that an individual participates in sport. Individuals with children present in the home are about $12 \%$ less likely to participate in sport than households with no children present. However, controlling for the presence of children, the more time that children spend practicing sport, the more likely the individual is to participate. This second result suggests that physically active children have an effect on the activity level of their parents. However, the overall effect of the presence of children is unclear, since the two effects offset each other. The family structure model also includes an indicator variable for single people in order to capture the effects of marital status on sport participation. The omitted category is married and cohabitating couples. Marital status appears to have no effect on participation in physical activity.
The final probit model on Table 2 adds a set of variables that reflect time constraints faced by individuals in the survey. These include the time required to travel to sports facilities, hours worked per week, hours spent taking care of children per week, and hours spent taking care of other relatives per week. The results, shown in the last two columns on Table 2 indicate that time constraints also affect the probability that an individual participates in sport. Each additional hour spent either taking care of children or taking care of other relatives reduces the probability that an individual participates in sport in this population. The effect of caring for other relatives is somewhat larger than the effect of taking care of children. Interestingly, the farther an individual must travel to reach the facility where the sporting activity takes place, the more likely is the individual to participate. This may reflect intensity of interest and commitment to participation in sport in this population. Since individuals who must travel farther are more likely to participate, these individuals must be particularly interested in participating in sport. Hours of work has no effect on the probability that an individual participates in sport. This could be due to limited variation in the hours worked variable in this sample. Another explanation is that hours devoted to work are not a part of the hours available for leisure and hence do not influence decisions about sport participation.

In general, the probit results indicate that both family structure and time constraints have an important effect on participation in sport. The presence of children in the home and the amount of time those children spend participating in sport both affect the probability that an individual in this population participates in sport. In terms of time constraints, both childcare and caring for relatives appear to make it more difficult for individuals to participate in sport. The full budget constraint discussed above shows that individuals have a limited amount of both time and money, and in this population, time spent caring for children or other relatives have a negative impact on sport participation. In the next section, we explore the effects of family structure on time spent in sport participation.

\section{Family structure and time spent}

The theoretical model developed above shows how decisions about participation in physical activity involve both intensive and extensive margins; individuals must decide to participate or not to participate, and also decide how long to spend in physical activity. The probit models identify factors that affect the participation decision. However, the probit model cannot provide any insight into the factors that affect the amount of time an individual decides to spend participating in physical activity, as the dependent variable for a probit model is dichotomous. 
In this population, the variable indicating the amount of time spent participating in sport participation, in terms of hours spent per week, will have a large number of values of zero because of the presence of non-participants. An empirical analysis of the determinants of time spent must account for the presence of these zeros. As discussed above, we use a Tobit model to analyze the determinants of time spent participating in sport. The Tobit model is a maximum likelihood estimator that accounts for censoring, in this case at zero because of non-participation. Table 3 contains the parameter estimates and the $p$ values for a twotailed test of the null hypothesis that the parameter estimates are equal to zero for two Tobit models. The "baseline" Tobit model contains the same explanatory variables as the "baseline" probit model in the previous section. The second Tobit model adds variables capturing family structure to the baseline model. As was the case for the probit models, the estimation and reporting strategy pursued is to estimate the "baseline" model first to permit an assessment of the consistency of the results with previous studies and the robustness of the commonly included covariates to the addition of the new family structure variables.

Note that we cannot estimate a model with time constraints in this case, because the variables capturing time constraints will be correlated with the unobservable factors affecting the time spent decision. Correlation between explanatory variables and the equation error term lead to serious statistical problems: bias and inconsistency.

The parameter estimates from the time spent tobit model contain several interesting features. Although the baseline model indicates little relationship between age and time spent participating practicing sport, the extended model shows that the relationship between age and time spent has the same inverse $U$ shape as the participation decision.
Time spent participating in sport at first increases with age and then decreased after peaking sometime in middle age. Males and females spend the same amount of time participating practicing sport. The amount of time spent participating in sport rises with education, although the effect only shows up at higher levels of education. Native Germans spend more time practicing sport.

Given the large number of explanatory variables in the family structure model reported in Table 3, the issue of multicollinearity might appear to be important. To assess the existence of any collinearity among the explanatory variables, we calculated the variance inflation factors (VIFs) for the family structure model. VIFs are a standard diagnostic test for multicollinearity that reflect the linear dependence among groups of variables. The VIFs for age and age squared are, as expected, large: 40 and 36, respectively. However, these variables are closely related by construction and simply capture the nonlinear effect of age on leisure time sport participation. The VIFs for all other variables are less than 3 . The standard critical value for VIFs is 10 , suggesting that multicollinearity is not an issue in this sample.

The interesting results in Table 3 relate to the effects of family structure on time spent practicing sport and show similar patterns to the probit results in Table 2. The presence of children in the home reduces the amount of time spent engaging in sporting activities by about $45 \mathrm{~min} /$ week. However, the time children spend practicing sports each week is associated with the surveyed time adult spend participating in sport each week. Coupled with the participation results in Table 2, the Tobit results contain strong evidence of spillover effects from sport participation between children and adults. We lack data to investigate the underlying mechanism that generates this result, but, in this population, there appears to be a clear association between
Table 3 Tobit results - time spent (hours per week)

\begin{tabular}{lccccc}
\hline & \multicolumn{2}{l}{ Baseline model } & & \multicolumn{2}{l}{ Family structure } \\
\cline { 2 - 3 } \cline { 5 - 5 } & Coefficient & $p$ Value & & Coefficient & $p$ Value \\
\hline Age & 0.034 & 0.062 & 0.045 & 0.020 \\
Age squared & 0.000 & 0.029 & & -0.001 & 0.009 \\
Male & 0.076 & 0.509 & & 0.049 & 0.670 \\
Employed & -0.001 & 0.995 & & 0.024 & 0.877 \\
Education (12-13 years) & 0.260 & 0.071 & & 0.259 & 0.072 \\
Education (>17 years) & 0.319 & 0.066 & & 0.343 & 0.047 \\
Native & 0.793 & 0.001 & & 0.752 & 0.002 \\
Single & & & -0.177 & 0.365 \\
Has kids & & & -0.742 & 0.000 \\
Household size & & & 0.061 & 0.418 \\
Kids active (h/week) & 1453 & & 0.185 & 0.020 \\
$N$ & & & & \\
\hline
\end{tabular}


active children and physically active adults. Again, the overall effect of children on time spent by adults in participating in sport is unclear, as the presence of children reduces time spent while active children increase the time adults spend practicing sport.

\section{Conclusions}

Recent research on the determinants of participation in sports has focused on the role played by economic factors. Much of this literature has focused on factors like income, education, and proximity to facilities. In this paper, the role played by time constraints and family structure is examined, two important and relatively overlooked economic factors that may affect participation in physical activity. Time constraints work through the full budget constraint faced by individuals, which limits both available time and available economic resources. Family structure works indirectly through the full budget constraint, both by adding economic resources for households with more than one earner and by increasing both time and income constraints when children are present.

Much of the previous empirical research has used publicly available secondary data to investigate the determinants of participation in physical activity. In this research, a unique primary data source, a CATI telephone survey conducted in the community of Rheinberg, Germany is used. The survey instrument contained detailed questions about participation and time spent in sport, family structure and time allocation making it possible to develop evidence about the interplay of family structure and time constraints on decisions about physical activity.

The results from the "baseline model" for the Rheinberg population are largely consistent with those found in other settings. Of more interest, however, are the findings about the role of family structure and time constraints on sport participation and physical activity. Evidence of a spillover effect from children's participation to adult participation has not been found in other studies. This result deserves further investigation in other, generally representative populations as it suggests a more complex mechanism at work between family structure and physical activity. The results also confirm the importance of time constraints on sport participation. Of particular interest is the finding that it is not only caring for children that negatively affects the likelihood of sport participation but also caring for relatives. Caring for relatives will become increasingly important as the population ages and deserves additional attention. Finally, hours worked does not affect participation or time spent confirming that physical activity is a leisure time activity. The critical time allocation decision faced by individuals is made on the non-work hours margin.
A limitation of this study is the sample which consists of residents from a single locality. This limits the generalizability of the results to other German populations and limits the ability to discuss policy implications for increasing sport participation. Nonetheless, even though the Rheinberg population is relatively homogeneous, economic and sociodemographic factors as well as family structure and time constraints are found to affect physical activity decisions. This is an important finding because the collection of information about family structure and time allocation are not always included in larger surveys. Finding that these variables are important in the Rheinberg population emphasizes the value of carrying out such surveys in other communities. The results from this study highlight the potential to learn more about the interplay of family structure and time constraints on sport participation by collecting the same information in other communities.

\section{References}

1. WHO (2010) Physical inactivity: a global public health problem. http://www.who.int/dietphysicalactivity/factsheet_inactivity/en/ index.html. Accessed 22.10.2010

2. Wicker P, Breuer C, Pawlowski T (2009) Promoting sport for all to age-specific target groups: the impact of sport infrastructure. European Sport Management Quarterly 9(2):103118

3. Kligerman M, Sallis JF, Ryan S, Lawrence FD, Nader PR (2007) Association of neighborhood design and recreation environment variables with physical activity and body mass index in adolensencts. Am J Heal Promot 21(4):274-277

4. Klein T (2009) Determinanten der Sportaktivität und der Sportart im Lebenslauf. KZfSS Kölner Zeitschrift für Soziologie und Sozialpsychologie 61(1):1-32

5. Downward P, Riordan J (2007) Social interactions and the demand for sport: an economic analysis. Contemporary Economic Policy 25(4):518-537

6. Humphreys BR, Ruseski JE (2009) The economics of participation and time spent in physical activity (Working Paper 2009-09). University of Alberta, Department of Economics, Edmonton

7. Leslie E, Cerin E, Gore CJ, St. George A, Bauman A, Owen N (2004) Gender, age and educational-attainment differences in australian adults' participation in vigorous sporting and fitness activities. J Phys Act Heal 1(4):377-388

8. SportEngland (2009) Active people 2: a summary of sports participation indicators. Sport England. http://www.sportengland. org/research/active people survey/active people survey 2.aspx. Accessed 15.07.2009

9. Haug E, Torsheim T, Sallis JF, Samdal O (2008) The characteristics of the outdoor school environment associated with physical activity. Heal Educ Res 25(2):248-256. doi:10.1093/her/cyn050

10. Gratton C, Tice A (1991) The demand for sport: a two-stage econometric model estimated from the health and lifestyle survey. Manchester Polytechnic, Department of Economics Discussion Paper, Manchester

11. Humphreys BR, Ruseski JE (2007) Participation in physical activity and government spending on parks and recreation. Contemporary Economic Policy 25(4):538-552 
12. Taks M, Scheerder J (2006) Youth sports participation styles and market segmentation profiles: evidence and applications. European Sport Management Quarterly 6(2):85-121

13. Berger IE, O'Reilly N, Parent MM, Séguin B, Hernandez T (2008) Determinants of sport participation among Canadian adolescents. Sport Management Review 11(3):277-307. doi:10.1016/S1441-3523(08)70113-X

14. Allender S, Cowburn G, Foster C (2006) Understanding participation in sport and physical activity among children and adults: a review of qualitative studies. Heal Educ Res 21(6):826-835

15. Dishman RK, Sallis JF, Orenstein DR (1985) The determinants of physical activity and exercise. Public Health Reports 100(2):158 171

16. Stamatakis E, Chaudhury M (2008) Temporal trends in adults' sports participation patterns in England between 1997 and 2006: the Health Survey for England. British Journal of Sports Medicine 42(11):901-908. doi:10.1136/bjsm.2008.048082

17. Sallis JF, Prochaska JJ, Taylor WC (2000) A review of correlates of physical activity of children and adolescents. Medicine and Science in Sports and Exercise 32:963-975

18. Eberth B, Smith MD (2010) Modelling the participation decision and duration of sporting activity in Scotland. Econ Model 27 (4):822-834

19. Pratt M, Macera CA, Blanton C (1999) Levels of physical activity and inactivity in children and adults in the United States: current evidence and research issues./Niveaux d'activite et d'inactivite physique chez des enfants et des adultes aux Etats-Unis. Medicine \& Science in Sports \& Exercise 31(11 Suppl):S526-s533

20. Downward P (2007) Exploring the economic choice to participate in sport: results from the 2002 general household survey. Int Rev Appl Econ 21(5):633-653

21. Sternfeld B, Ainsworth BE, Quesenberry CP (1999) Physical activity in a diverse population of women. Preventive Medicine 28(3):313-323

22. Farrell L, Shields MA (2002) Investigating the economic and demographic determinants of sporting participation in England. Journal of the Royal Statistical Society (Series B) 165(2):335-348

23. Hovemann G, Wicker P (2009) Determinants of sport participation in the European Union. European Journal for Sport and Society 6(1):49-57

24. Lee YG, Bhargava V (2004) Leisure time: do married and single inividuals spend it differently? Fam Consum Sci Res J 32(3):254274

25. Gratton C, Taylor P (2000) Economics of sport and recreation. E \& FN Spon, London
26. Seabra AF, Mendonca DM, Thomis MA, Peters TJ, Maia JA (2007) Associations between sport participation, demographic and socio-cultural factors in Portuguese children and adolescents. European Journal of Public Health 18(1):25-30

27. Coleman L, Cox L, Roker D (2008) Girls and young women's participation in physical activity: psychological and social influences. Heal Educ Res 23(4):633-647

28. Schor EL (1995) The influence of families on child health. Family behaviors and child outcomes. Pediatr Clin N Am 42(1):89-102

29. Booth ML, Owen N, Bauman A, Clavisi O, Leslie E (2000) Social-cognitive and perceived environment influences associated with physical activity in older Australians. Preventive Medicine 31(1):15-22

30. Downward P, Dawson A, Dejonghe T (2009) Sport economics. Theory, evidence and policy. Butterworth-Heinemann, Oxford

31. Erlinghagen M (2003) Wer treibt Sport im geteilten und vereinten Deutschland? Eine quantitative Analyse sozio-ökonomischer Determinaten des Breitensports, vol 4, Graue Reihe des Instituts Arbeit und Technik. Institut für Arbeit und Technik, Gelsenkirchen

32. Sallis JF, Owen N (1999) Physical Activity \& Behavioral Medicine. Sage, Thousand Oaks

33. Pawlowski T, Breuer C, Wicker P, Poupaux S (2009) Travel time spending behaviour in recreational sports: an econometric approach with management implications. European Sport Management Quarterly 9(3):215-242

34. Norman GJ, Nutter SK, Ryan S, Sallis JF, Calfas KJ, Patrick K (2006) Community design and access to recreational facilities as correlates of adolescent physical activity and body-mass index. J Phys Act Heal 3(1):118-128

35. Humpel N, Owen N, Leslie E (2002) Environmental factors associated with adults' participation in physical activity: a review. American Journal of Preventive Medicine 22(3):188-199

36. Limstrand T, Reher NJ (2008) Young people's use of sports facilities: a Norwegian study on physical activity. Scandinavian Journal of Public Health 36(5):452-459

37. Becker GS (1965) A theory of the allocation of time. Econ J 75 (3):493-517

38. Jones AM (2000) Health econometrics. Handb Heal Econ 1:265344

39. Wetterich J, Schrader H, Eckl S (2007) Regionale Sportentwicklungsplanung im Landkreis Groß-Gerau: Projektdokumentation zur 3. Fortschreibung des Sportentwicklungsplanes für den Landkreis Groß-Gerau. Lit, Wien

40. Hübner H, Wulf O (2009) Grundlagen der Sportentwicklung in Bielefeld. FIT, Berlin 